\title{
Rapid electrochemical platform for nicotine sensing in cigarettes and chewing gums
}

\author{
Kristína Cinkováa ${ }^{\mathrm{a}}$ Linda Dianováa, Marian Vojs ${ }^{\mathrm{b}}$, \\ Marián Marton ${ }^{\mathrm{b}}$, L'ubomír Švorc ${ }^{\mathrm{a}}$ \\ ${ }^{a}$ Institute of Analytical Chemistry, Faculty of Chemical and Food Technology, \\ Slovak University of Technology in Bratislava, Radlinského 9, SK-812 37 Bratislava, Slovak Republic \\ ${ }^{b}$ Institute of Electronics and Photonics, Faculty of Electrical Engineering and Information Technology, \\ Slovak University of Technology in Bratislava, Ilkovičova 3, SK-812 19 Bratislava, Slovak Republic \\ kristina.cinkova@stuba.sk \begin{abstract}
at boron-doped diamond electrode was developed. The effect of $\mathrm{pH}$ of supporting electrolyte, scan rate and square-wave voltammetric parameters was examined. Behavior study revealed that nicotine provided two irreversible oxidation peaks, the first one well-shaped at $+1.14 \mathrm{~V}$ and the second one poorly-defined at $+1.61 \mathrm{~V}$ vs. $\mathrm{Ag} / \mathrm{AgCl}$ electrode in the presence of phosphate buffer ( $\mathrm{pH} 9.0$ ). Under optimal experimental conditions (modulation amplitude of $40 \mathrm{mV}$, frequency of $50 \mathrm{~Hz}$ and scan rate of $0.225 \mathrm{~V} \cdot \mathrm{s}^{-1}$ ), the current response of nicotine was proportionally linear in the concentration range from $9.9 \times 10^{-6}$ to $1.7 \times 10^{-4} \mathrm{~mol} \cdot \mathrm{L}^{-1}\left(R^{2}=0.996\right)$ with the detection limit of $6.1 \times 10^{-6} \mathrm{~mol} \cdot \mathrm{L}^{-1}\left(0.989 \mathrm{mg} \cdot \mathrm{L}^{-1}\right)$ and the relative standard deviation of $8.8 \%$ (number of measurements $n=10,5.7 \times 10^{-5} \mathrm{~mol} \cdot \mathrm{L}^{-1}$ nicotine). The proposed procedure was applied to the quantification of nicotine in cigarettes and chewing gums with the determined values in good agreement with those declared by producer. In this respect, the developed protocol could represent an effective and rapid alternative to chemically modified electrodes in analysis of alkaloids.
\end{abstract} \\ Abstract: A novel protocol for the simple and rapid determination of nicotine using square-wave voltammetry
}

Keywords: nicotine, boron-doped diamond electrode, square-wave voltammetry, detection limit

\section{Introduction}

Nicotine ([3-(2S)-1-methylpyrrolidin-2-yl)pyridine) belongs to pyridine alkaloids obtained from the plant Nicotiana tabacum (Geto et al., 2012). This substance stimulates brain activity, increases the activity of smooth muscles or synthesis of endorfines and therefore can be used in therapy of some neurodegenerative processes (Stočes and Švancara, 2014). However, nicotine exhibits negative effects on human health. The frequent intake of nicotine leads to many potential diseases such as increased blood pressure and heart beat, atherosclerosis of the respiratory organs, and stimulation of the central nervous system leading to disruption of arteries and cardiovascular risk factors. Smoking contributes heavily to the mortality burden because it is a major cause of vascular disease, cancer and chronic obstructive pulmonary disease (Kassa et al., 2013). Therefore, rapid and reliable determination of nicotine is still necessary and constitutes a current challenge for analytical chemists.

Determination of nicotine is mostly carried out by means of modern separation techniques such as gas chromatography (Hossain and Salehuddin, 2013) and high-performance liquid chromatography (Wei et al., 2014), capillary electrophoresis (SánchezHernández et al., 2014), imunological methods
(Dhar, 2004), spectrophotometry (Yasuda et al., 2013) as well as electrochemical methods (Švorc et al., 2014ab). Chromatographic and immunological methods are both sensitive but are also expensive, time-consuming, lab-based techniques requiring skilled operators. In this sense, electrochemical methods can boast low instrumental costs, relatively simple operation, miniaturisation and rapid response (Švorc et al., 2015).

A survey of the literature shows many studies dealing with electroanalytical determination of nicotine and other related alkaloids. These procedures utilize mostly various carbonaceous electrodes together with suitable modifiers in order to improve reaction kinetics and sensitivity. In this sense, a poly(4-amino-3-hydroxynaphtalene sulfonic acid)modified glassy carbon electrode was developed for the voltammetric determination of nicotine with low detection limit (LOD) of $8.6 \times 10^{-7} \mathrm{~mol} \cdot \mathrm{L}^{-1}$. Application of the proposed method to cigarette samples gave acceptable recovery results (Geto et al., 2012). Electrochemical behavior of nicotine was studied using carbon paste electrode. The LOD was found to be $2.5 \times 10^{-5} \mathrm{~mol} \cdot \mathrm{L}^{-1}$ and the method was applied to a set of refilling liquids for electronic cigarettes (Stočes and Švancara, 2014). Levent et al. (2009) described a method for the determination of nicotine using pencil graphite electrode in the presence of 
anionic surfactant with LOD of $2.0 \times 10^{-6} \mathrm{~mol} \cdot \mathrm{L}^{-1}$. In recent years, several electrochemical biosensors were constructed for determination of nicotine (Campanella et al., 2001; Highton et al., 2009). The lowest LOD of $5.5 \times 10^{-11} \mathrm{~mol} \cdot \mathrm{L}^{-1}$ with wide linear concentration range from $1.8 \times 10^{-10}$ to $1.0 \times 10^{-3} \mathrm{~mol} \cdot \mathrm{L}^{-1}$ were obtained by a sensor based on an interaction of bovine serum albumine with nicotine (Liang et al., 2012).

Boron-doped diamond (BDD) is one of the new promising materials for electrochemicalapplications due to its unique and extremely useful properties, such as high chemcial stability and hardness, biocompatibility, very low and stable capacitive current and resistance to fouling (Cinková et al., 2015a). Recently, Švorc et al. (2014a) developed a sensitive and reliable method for the determination of nicotine on commercially available BDD electrode using differential pulse voltammetry with a LOD of $3.0 \times 10^{-7} \mathrm{~mol} \cdot \mathrm{L}^{-1}$. The electrochemical behavior of nicotine in alkaline media was also explored using an anodically pretreated BDD electrode by Suffredini et al. (2005). The method was applied to the determination of nicotine in cigarette tobacco.

The aim of this work was to study the electrochemical behavior and to explore the possibilities of simple and rapid analytical determination of nicotine based on BDD electrode using square-wave voltammetry. The proposed method was applied to the quantification of nicotine in cigarettes and chewing gums.

\section{Materials and Methods}

Cyclic voltammetric (CV) and square-wave voltammetric (SWV) measurements were performed using an electrochemical system Autolab PGSTAT-302N (Metrohm Autolab B.V., The Netherlands), controlled by the software NOVA (version 1.8). The cell consisted of a three-electrode system: a BDD electrode (inner diameter of BDD film of $740 \mu \mathrm{m}, \mathrm{B} / \mathrm{C}$ ratio in gas phase of $20000 \mathrm{ppm}$ ) a Pt wire counter electrode and an $\mathrm{Ag} / \mathrm{AgCl} / 3 \mathrm{~mol} \cdot \mathrm{L}^{-1} \mathrm{KCl}$ reference electrode to which all electrode potentials hereinafter are referred. All pH values were measured using a pH meter Model 215 (Denver Instrument, USA) with a combined electrode (glass-reference electrode).

Nicotine was obtained from Roth (Karlsruhe, Germany) and used without any further purification. Its stock solution $\left(1.0 \times 10^{-3} \mathrm{~mol} \cdot \mathrm{L}^{-1}\right)$ was prepared using double-distilled water. The solutions of lower concentrations were prepared from the stock solution by appropriate dilution with supporting electrolyte. Phosphate buffers $\left(0.1 \mathrm{~mol} \cdot \mathrm{L}^{-1}, \mathrm{pH} 2-11\right)$ were used as supporting electrolytes. The pHs of buffers were adjusted with sodium hydroxide $\left(0.2 \mathrm{~mol} \cdot \mathrm{L}^{-1}\right)$. All reagents used were of analytical grade purity.

Commercial cigarettes (samples C1-C3) with various nicotine content (as declared by producer) were purchased in a local supermarket. Tobacco from ten cigarettes of each brand was mixed and weighed in order to get an average weight of one cigarette. Subsequently, the aliquot amount (1.011 g) was placed into the beaker together with $20 \mathrm{~mL}$ of double-destilled water and pretreated in ultrasonic bath (Elmasonic S60 H, Germany) for $30 \mathrm{~min}$, filtered and afterwards diluted to $50 \mathrm{~mL}$. An aliquot of $5 \mathrm{~mL}$ (or $10 \mathrm{~mL}$ for the lowest nicotine content in cigarettes) of the clear filtrate of each sample was added to the voltammetric cell containing 20 (or 30) $\mathrm{mL}$ of supporting electrolyte and the voltammograms were recorded.

Nicotine-containing chewing gums (G1) were purchased in local pharmacy. Five chewing gums were weighed and cut into small pieces. An aliquot of $1.223 \mathrm{~g}$ was dissolved in $20 \mathrm{~mL}$ of hexane and quantitatively extracted with $20 \mathrm{~mL}$ of the supporting electrolyte. The residues were rinsed and subsequently, the combined extract was filtered and made up to $100 \mathrm{~mL}$ with supporting electrolyte in a volumetric flask. An aliquot of $3 \mathrm{~mL}$ was added to electrochemical cell containing $25 \mathrm{~mL}$ of supporting electrolyte and analyzed.

At the beginning of every work day, the BDD electrode surface was rinsed with deionized water and activated by $10 \mathrm{CV}$ scans in the potential range from $-2.0 \mathrm{~V}$ to $+2.0 \mathrm{~V}$ in $0.5 \mathrm{~mol} \cdot \mathrm{L}^{-1}$ sulphuric acid. Using optimal experimental parameters, SW voltammograms were recorded. Every point of the calibration curve represents the average of three successive measurements of corresponding calibration solution of nicotine. The linear least-squares regression (OriginPro 8.5, OriginLab Corporation, USA) was used for the assessment of calibration curves and the relevant results (slope and intercept) were reported with a confidence interval for $95 \%$ probability. The detection limit (LOD) was calculated as three times the standard deviation of the intercept divided by the slope of calibration curve. The real sample analysis was performed by the standard addition method with tripple addition of $1 \mathrm{~mL}$ of the nicotine standard solution.

\section{Results and Discussion}

Initially, CV studies were performed in order to explore the basic voltammetric characteristics of nicotine $\left(1.0 \times 10^{-4} \mathrm{~mol} \cdot \mathrm{L}^{-1}\right)$ at $\mathrm{BDD}$ electrode. For this purpose, phosphate (PB, pH 2.0-11.0) buffers were used. In the presence of acidic 
media ( $\mathrm{pH}$ 2-5) no significant current response of the analyte was observed. At pH 8 and higher, nicotine provided two irreversible oxidation peaks, however, the background current was appeared to be considerably higher. The highest peak current of nicotine was observed at $\mathrm{pH} 9$, hence, it was selected as a suitable supporting electrolyte for further experiments. Moreover, at this $\mathrm{pH}$, two irreversible oxidation peaks were noticed only in the first scan and subsequently in next scans the second one disappeared. Fig. 1 shows the first $\mathrm{CV}$ scan of $1.0 \times 10^{-4} \mathrm{~mol} \cdot \mathrm{L}^{-1}$ nicotine in $\mathrm{PB}(\mathrm{pH} 9)$ with the first distinct oxidation peak at the potential of $+1.14 \mathrm{~V}$ and the second-one poorly defined at $+1.61 \mathrm{~V}$ vs. $\mathrm{Ag} / \mathrm{AgCl}$. Using this $\mathrm{pH}$, the effect of scan rate was evaluated (Fig. 2). With increasing scan rate (in the range of $10-200 \mathrm{mV} \cdot \mathrm{s}^{-1}$ ), peak current of nicotine becomes higher with the slight shift of peak poten-

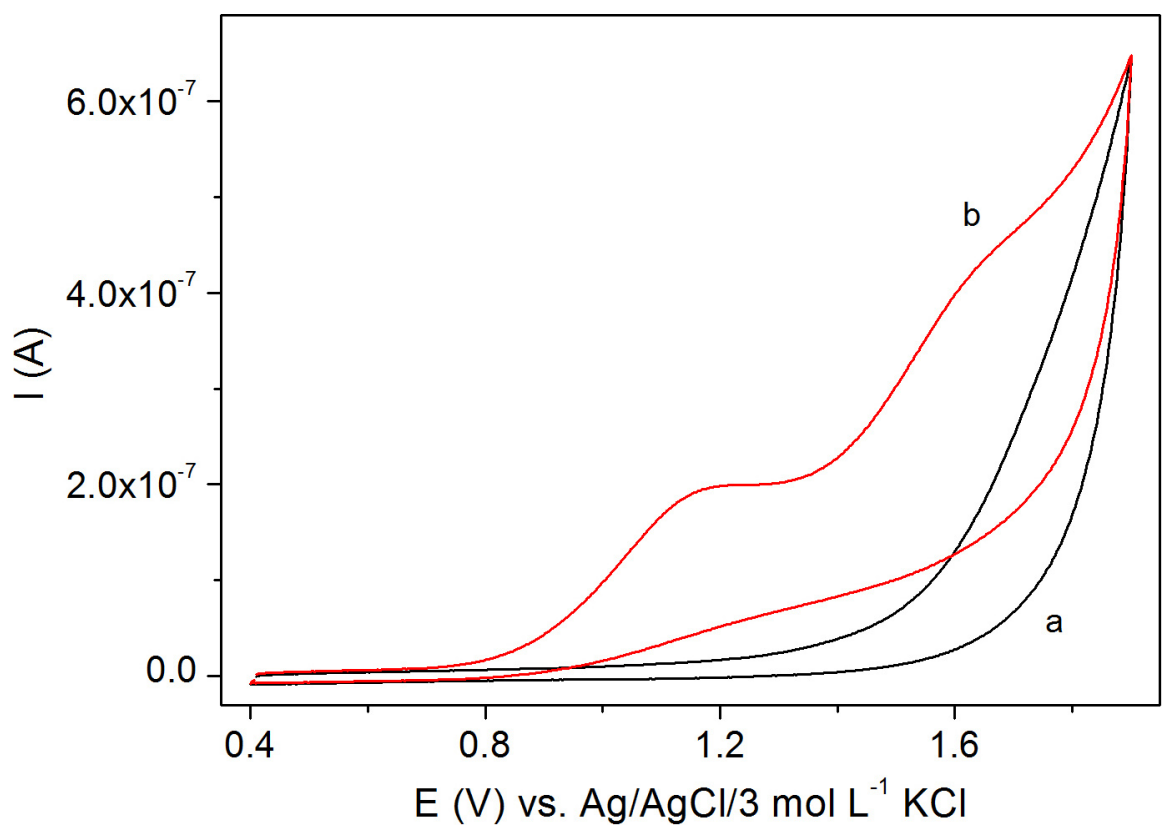

Fig. 1. Cyclic voltammograms of (a) blank ( $\mathrm{PB}, \mathrm{pH}$ 9) and (b) $1.0 \times 10^{-4} \mathrm{~mol} \cdot \mathrm{L}^{-1}$ nicotine in $\mathrm{PB}(\mathrm{pH} 9)$ at BDD electrode with a scan rate of $100 \mathrm{mV} \cdot \mathrm{s}^{-1}$.

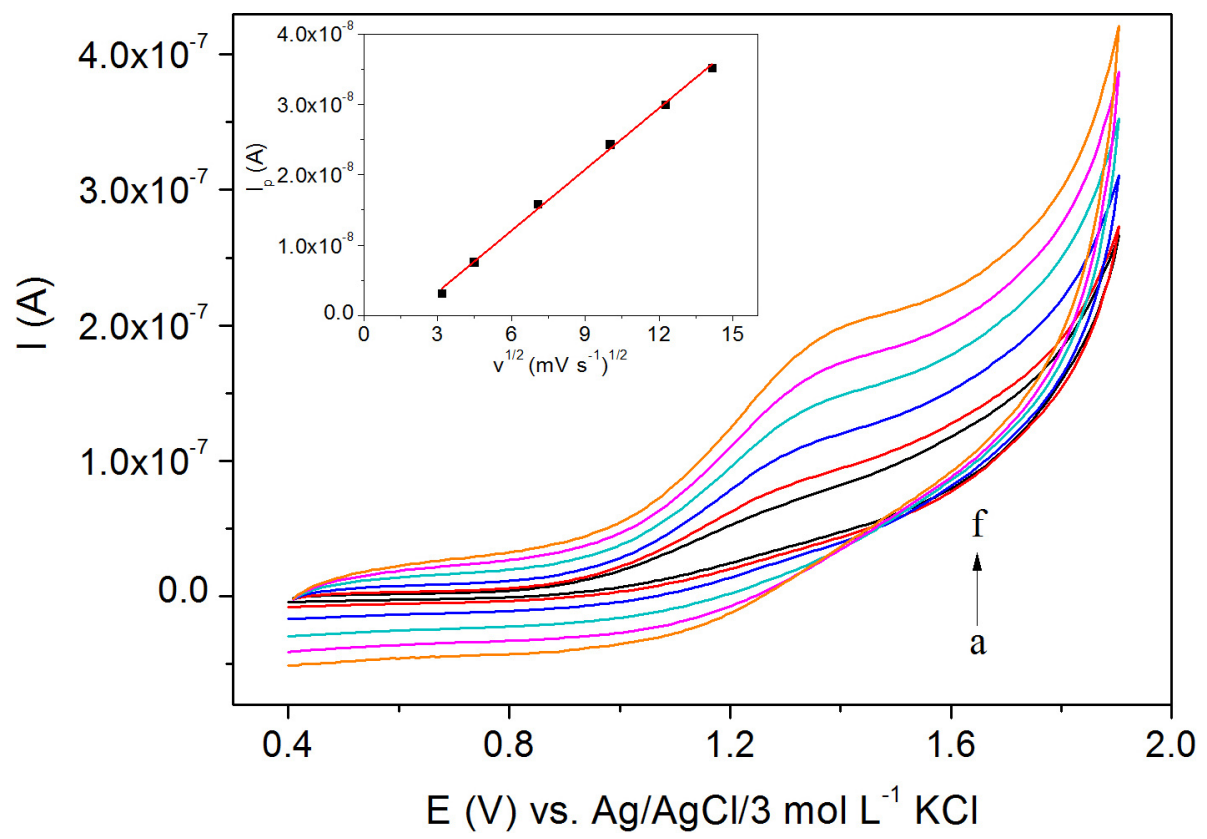

Fig. 2. Cyclic voltammograms of $1.0 \times 10^{-4} \mathrm{~mol} \cdot \mathrm{L}^{-1}$ nicotine for scan rates (v): (a) 10, (b) 20, (c) 50, (d) 100, (e) 150 and (f) $200 \mathrm{mV} \cdot \mathrm{s}^{-1}$ in $\mathrm{PB}\left(\mathrm{pH}\right.$ 9) at BDD electrode. The peak current $I_{p}$ as a function of square root of the scan rate $v^{1 / 2}$ appears in the inset. 
tial to positive values that is typical for irreversible systems (Švorc et al., 2014b). Moreover, it was found that the oxidation peak current varies linearly with the square root of scan rate (inset of Fig. 2), indicating the diffusion-controlled nature of the electrode process. The linear dependence obeys the following equation (1):

$$
\begin{gathered}
I_{p}(\mathrm{~A})=(-5.53 \pm 0.23) \times 10^{-9}+ \\
+(2.90 \pm 0.08) \times 10^{-9} \times v^{1 / 2}\left(\mathrm{mV} \cdot \mathrm{s}^{-1}\right), \\
\mathrm{R}^{2}=0.997
\end{gathered}
$$

The optimization of SWV parameters influencing the current response of analyte is an important step in the development of electroanalytical methodology (Cinková et al., 2015b). For this purpose, instrumental parameters such as amplitude (in the range of $10-150 \mathrm{mV}$ ) and frequency (in the range of $10-150 \mathrm{~Hz}$ ) were optimized using $1 \times 10^{-4} \mathrm{~mol} \cdot \mathrm{L}^{-1}$ nicotine in $\mathrm{PB}(\mathrm{pH} 9)$. The selected optimal experimental conditions were as follows: amplitude of $40 \mathrm{mV}$, frequency of $50 \mathrm{~Hz}$ and scan rate of $0.225 \mathrm{~V} \cdot \mathrm{s}^{-1}$. In the next step, these values were used for SWV calibration curve construction. After the optimization, calibration curve was constructed by plotting peak current against concentration of nicotine in the range from $9.9 \times 10^{-6}$ to $1.7 \times 10^{-4} \mathrm{~mol} \cdot \mathrm{L}^{-1}$. The respective $\mathrm{SW}$ voltammograms with the corresponding analytical curve are displayed in Fig. 4. The analytical parameters are summarized in Table 1. It can be taken into account that the achieved LOD value was obtained without any chemical modification of working electrode. The precision of measurement was evaluated from intra-day repeatability assays. For this, 10 successive SWV measurements were performed for $5.7 \times 10^{-5} \mathrm{~mol} \cdot \mathrm{L}^{-1}$ nicotine. The RSD (8.8\%) demonstrated the stable voltammetric response of working electrode to nicotine sensing. Thus, BDD has proven to be suitable electrochemical platform for the sufficiently precise quantification of nicotine.

Tab. 1. Analytical parameters for the determination of nicotine by SWV in $\mathrm{PB}(\mathrm{pH} 9)$ at the BDD electrode $(n=3)$.

\begin{tabular}{lc}
\hline Analytical parameter & Value \\
\hline Intercept $(\mathrm{A})$ & $(29.2 \pm 0.4) \times 10^{-9}$ \\
Slope $\left(\mathrm{A} \cdot \mathrm{L} \cdot \mathrm{mol}^{-1}\right)$ & $(20.7 \pm 0.4) \times 10^{-5}$ \\
Linear concentration range $\left(\mathrm{mol} \cdot \mathrm{L}^{-1}\right)$ & $9.9 \times 10^{-6}-1.7 \times 10^{-4}$ \\
Coefficient of determination & 0.996 \\
Detection limit $\left(\mathrm{mol} \cdot \mathrm{L}^{-1}\right)$ & $6.1 \times 10^{-6}$ \\
Repeatability $(\%)^{*}$ & 8.8 \\
\hline
\end{tabular}

${ }^{*}$ RSD calculated for 10 replicate of measurements using $5.7 \times 10^{-5} \mathrm{~mol} \cdot \mathrm{L}^{-1}$ nicotine.

Next, the possible interferences of some biomolecules were investigated under found operating conditions. The effect of caffeine, glucose, uric acid, acetylsalicylic acid, penicillin $\mathrm{V}$ and cholesterol on the peak current of $5.7 \times 10^{-5} \mathrm{~mol} \cdot \mathrm{L}^{-1}$ nicotine was

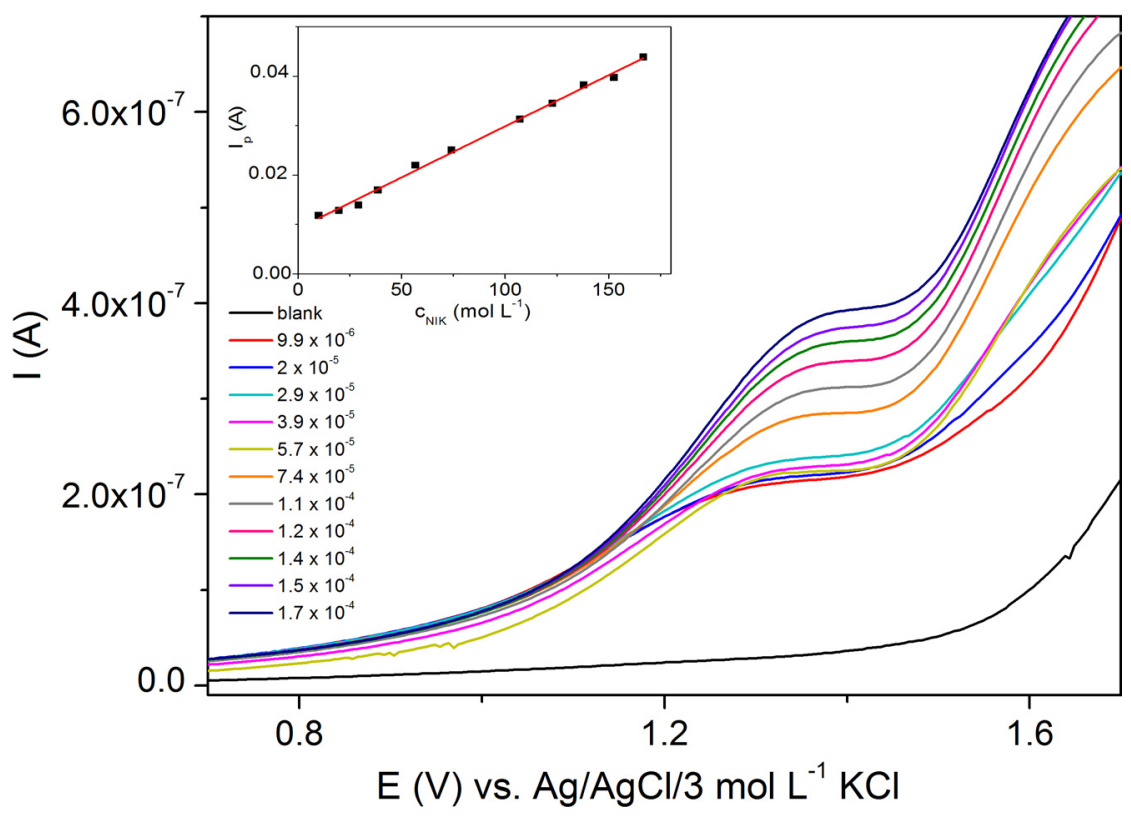

Fig. 3. SW voltammograms for the first oxidation peak of nicotine with various concentrations of solutions in PB ( $\mathrm{pH}$ 9) at BDD electrode with optimized SWV parameters: amplitude of $40 \mathrm{mV}$,

frequency of $50 \mathrm{~Hz}$ and scan rate of $0.225 \mathrm{~V} \cdot \mathrm{s}^{-1}$. The dependence between peak current and nicotine concentrations appears in the inset. 
explored. SWV measurements were undertaken in the absence and presence of each compound in the concentration ratios from $1: 0.1$ to $1: 100$. It was found that even in the presence of minor excess of some tested biomolecules, the current responses of nicotine were considerably influenced. The significant signal increase was recorded in 20 -fold excess of caffeine. Glucose and cholesterol were not electrochemically active at given experimental conditions, however, they caused the decline of quantification oxidation peak of nicotine. In the case of ascorbic acid, acetylsalicylic acid and penicillin $\mathrm{V}$, their oxidation peaks became enlarged and overlap with quantification peak of nicotine. Thus, the utilization of proposed method could be limited depending on the particular excess of compounds with similar oxidation potentials when compared to nicotine (e.g. in analysis of biological samples).

The developed voltammetric procedure was applied to the determination of nicotine in cigarettes and chewing gums using the standard addition method. SW voltammograms and respective standard addition curve obtained for nicotine-containing chewing gums (G1) analysis are depicted in Fig. 4. Taking the molecular mass of nicotine $\left(162.24 \mathrm{~g} \cdot \mathrm{mol}^{-1}\right)$ into account, the volume in electrochemical cell (28 $\mathrm{mL}$ ) and the dilution factor (33.3), the nicotine content was determined to be $4.043 \mathrm{mg}$ (content in equivalent portion of $1.223 \mathrm{~g}$ of chewing gum).
Regarding the average weight of one chewing gum $(1.267 \mathrm{~g})$, the average content of nicotine in one chewing gum is $4.192 \mathrm{mg}$. Subsequently, the proposed method was used to determine nicotine content in cigarettes. The obtained results for the three determinations are summarized in Table 2. As can be seen, excellent recoveries were obtained, ranging from 94.7 to $108.9 \%$. These results suggest the satisfactory feasibility of the proposed procedure for direct and rapid nicotine determination in cigarettes and chewing gums.

Tab. 2. Analysis of cigarettes and chewing gums with a declared amount of nicotine using the proposed method $(n=3)$.

\begin{tabular}{cccc}
\hline \multirow{2}{*}{ Sample } & \multicolumn{2}{c}{ Nicotine content $(\mu \mathrm{g})$} & \multirow{2}{*}{$\begin{array}{c}\text { Recovery } \\
(\%)\end{array}$} \\
\cline { 2 - 3 } & Declared & Found* & \multicolumn{1}{c}{108.9} \\
C1 & 400 & $(436 \pm 43)$ & 94.7 \\
C2 & 600 & $(568 \pm 34)$ & 104.1 \\
C3 & 800 & $(833 \pm 40)$ & 104.8 \\
G1 & 4000 & $(4192 \pm 150)$ & \\
\hline
\end{tabular}

${ }^{*}$ Coverage interval calculated according $\left(\bar{x} \pm t_{n-1, \alpha} \cdot\left(\mathrm{SD} / \mathrm{n}^{1 / 2}\right)\right)$; $\mathrm{t}_{2 ; 0.05}=2.92$.

\section{Conclusions}

In this study, the BDD electrode coupled with

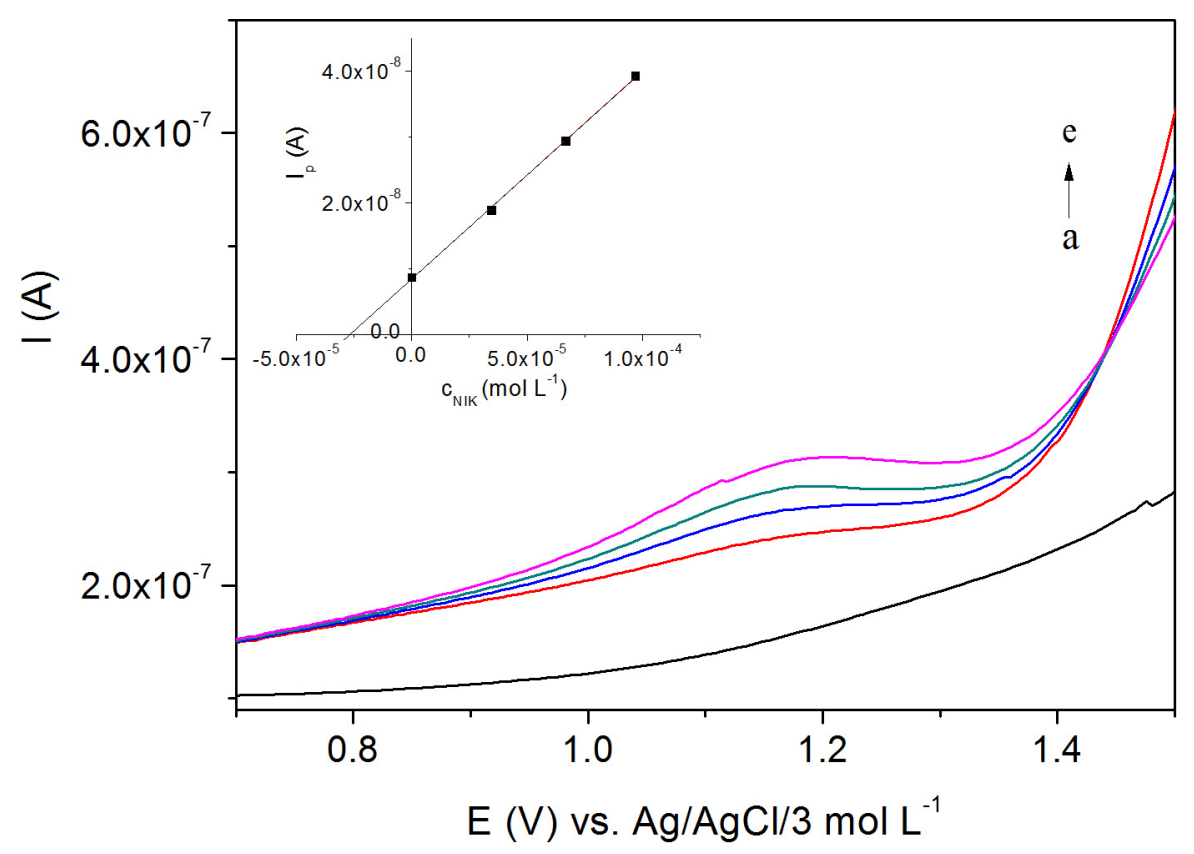

Fig. 4. SW voltammograms for chewing gums analysis with declared content of $4000 \mu \mathrm{g}$ nicotine using standard addition method in PB (pH 9) at BDD electrode: (a) blank, (b) after addition of $3 \mathrm{~mL}$ of chewing gums extract and after spiking of (c) 1 , (d) 2 and (e) $3 \mathrm{~mL}$ of $1 \times 10^{-3} \mathrm{~mol} \cdot \mathrm{L}^{-1}$ nicotine solution. SWV parameters: amplitude of $40 \mathrm{mV}$, frequency of $50 \mathrm{~Hz}$ and scan rate of $0.225 \mathrm{~V} \cdot \mathrm{s}^{-1}$.

The analysis by standard addition method is depicted in the inset. 
SWV mode as suitable electrochemical platform for rapid and simple analytical determination of nicotine in cigarettes and chewing gums was demonstrated. Cyclic voltammetry indicated that electrochemical behavior of nicotine proceeded in $\mathrm{PB}$ at $\mathrm{pH} 9$ as an irreversible process with oxidation peaks at +1.14 and $+1.61 \mathrm{~V}$ vs. $\mathrm{Ag} / \mathrm{AgCl}$ electrode, respectively. Obtained analytical parameters for the quantification peak of nicotine $(+1.14 \mathrm{~V})$ employing optimal experimental parameters were as follows: linear concentration range from $9.9 \times 10^{-6}$ to $1.7 \times 10^{-4} \mathrm{~mol} \cdot \mathrm{L}^{-1}$, the detection limit of $6.1 \times 10^{-6} \mathrm{~mol} \cdot \mathrm{L}^{-1}$ and the relative standard deviation of $8.8 \%\left(n=10,5.7 \times 10^{-5} \mathrm{~mol} \cdot \mathrm{L}^{-1}\right.$ nicotine $)$. Achieved recovery values (from 94.7 to $108.9 \%$ ) confirmed the satisfactory accuracy of the developed protocol. It can be concluded that proposed method may represent the electrochemical alternative to more complicated chemically modified electrodes in analysis of nicotine-containing commercial products.

\section{Acknowledgement}

This work has been supported by the Grant Agency of the Slovak Republic (grant No. 1/0051/13) and the Slovak Research and Development Agency under the contracts Nos. APVV-0797-11 and APVV-0365-12.

\section{References}

Campanella L, Favero G, Tomassetti M (2001) Anal. Lett. 34: 855-866.
Cinková K, Zbojeková N, Vojs M, Marton M, Samphao A, Švorc L' (2015a) Anal. Methods 7: 6755-3763.

Cinková K, Švorc L, Šatkovská P, Vojs M, Michniak P, Marton M (2015b) Anal. Lett. 46: 107-121.

Dhar P (2004) J. Pharm. Biomed. Anal 35: 155-168.

Geto A, Amare M, Tessema M, Admassie S (2012) Electroanalysis 3: 659-665.

Highton L, Kadara RO, Jenkinson N, Riehl BL, Banks CE (2009) Electroanalysis 21: 2387-2389.

Hossain AM, Salehuddin SM (2013) Arabian J. Chem. 6: 275-278.

Kassa H, Geto A, Admassie S (2013) Bull. Chem. Soc. Ethiop. 27: 321-328.

Levent A, Yardim Y, Senturk Z (2009) Electrochim. Acta 55: $190-195$.

Liang J, Han F, Chen Y (2012) Electrochem. Commun. 24: 93-96.

Sánchez-Hernández L, Hernández-Domínguez D, Bernal J, Neusüß Ch, Martín MT, Bernal JL (2014) J. Chromatogr. A 1359: 317-324.

Stočes M, Švancara I (2014) Electroanalysis 26: 26552663.

Suffredini HB, Santos MC, De Souza D, Codognoto L, Homem-de-Mello P, Honório KM, Silva ABF, Machado SAS, Avaca LA (2005) Anal. Lett. 38: 1587-1599.

Švorc L, Stanković DM, Kalcher K (2014a) Diamond Relat. Mater. 42: 1-7.

Švorc L, Cinková K, Sochr J, Vojs M, Michniak P, Marton M (2014b) J. Electroanal. Chem. 728: 86-93.

Švorc L, Cinková K, Samphao A, Stanković DM, Mehmeti E, Kalcher K (2015) J. Electroanal. Chem. 744: 37-44.

Wei B, Feng J, Rehmani I, Miller S, McGuffey JE, Blount BC, Wang L (2014) Clin. Chim. Acta 436: 290-297.

Yasuda M, Ota T, Morikawa A, Mawatari K, Fukuuchi T, Yamaoka N, Kaneko K, Nakagomi K (2013) J. Chromatogr. B 934: 41-45. 